Article

\title{
Enhancing Power System Frequency with a Novel Load Shedding Method Including Monitoring of Synchronous Condensers' Power Injections
}

\author{
Antans Sauhats ${ }^{1}$, Andrejs Utans ${ }^{1}$, Jurijs Silinevics ${ }^{1,2}$, Gatis Junghans ${ }^{2}$ and Dmitrijs Guzs ${ }^{1,2, *}$ \\ 1 Institute of Power Engineering, Riga Technical University, 12-k1 Azenes Street, LV-1010 Riga, Latvia; \\ sauhatas@eef.rtu.lv (A.S.); utan@eef.rtu.lv (A.U.); jurijs.silinevics@ast.lv (J.S.) \\ 2 AS Augstsprieguma Tikls (TSO), 86 Darzciema Iela, LV-1073 Riga, Latvia; gatis.junghans@ast.lv \\ * Correspondence: dmitrijs.guzs@ast.lv; Tel.: +371-67725361
}

Citation: Sauhats, A.; Utans, A.; Silinevics, J.; Junghans, G.; Guzs, D. Enhancing Power System Frequency with a Novel Load Shedding Method Including Monitoring of Synchronous Condensers' Power Injections. Energies 2021, 14, 1490. https:// doi.org/10.3390/en14051490

Academic Editor: Juri Belikov

Received: 15 February 2021

Accepted: 5 March 2021

Published: 9 March 2021

Publisher's Note: MDPI stays neutral with regard to jurisdictional claims in published maps and institutional affiliations.

Copyright: $\odot 2021$ by the authors. Licensee MDPI, Basel, Switzerland. This article is an open access article distributed under the terms and conditions of the Creative Commons Attribution (CC BY) license (https:// creativecommons.org/licenses/by/ $4.0 /)$.

\begin{abstract}
Under-frequency load shedding (UFLS) is a classic and a commonly accepted measure used to mitigate the frequency disturbances in case of loss-of-generation incidents in AC power grids. Triggering of UFLS is classically done at frequency thresholds when system frequency collapse is already close to happening. The renewed interest for synchronous condensers due to the global trends on massive commissioning of non-synchronous renewable power generation leading to reduction of system inertia gives an opportunity to rethink the approach used to trigger load-shedding activation. This question is especially relevant for the Baltic states facing a desynchronization from Russian power grid and a necessity to operate in an isolated island mode. The main goal of this paper is to introduce a predictive load shedding (LS) method without usage of either frequency or ROCOF measurements based on the monitoring of active power injections of synchronous condensers and to prove the efficiency of the concept through several sets of case study simulations. The paper shows that the proposed approach can provide a greatly improved frequency stability of the power system. The results are analyzed and discussed, the way forward for the practical implementation of the concept is sketched.
\end{abstract}

Keywords: power grid; inertia; load shedding; frequency stability; synchronous condensers; frequency collapse; PMU

\section{Introduction}

The topic of climate change and the ongoing efforts to combat it and to reduce anthropogenic greenhouse gas emissions have resulted in several high-level policies [1] aimed at reducing the usage of fossil fuels with a massive roll-out of renewable energy generation capacities. As the result the European Union (EU) has introduced and started to implement the 2030 Climate \& Energy Framework stating a 55\% net greenhouse gas emission reduction target with 1990 as the base year [2]. Under this framework Germany for example as one of largest economies of the EU plans to achieve ca. $190 \mathrm{GW}$ of non-synchronous renewable generation capacity installed in 2030 [3], comparing to $100 \mathrm{GW}$ non-synchronous renewable generation capacity and a peak load of ca. $80 \mathrm{GW}$ in 2018 [4]. These developments leading to higher and higher penetration of alternating current (AC) power systems by non-synchronous renewables are expected to bring a number of challenges as reduction of total system inertia, increasing rates of change of frequency (ROCOF), reduced frequency stability and a decreasing number of generation units providing primary and secondary frequency regulation $[5,6]$.

Frequency stability of AC power systems, together with the voltage and the transient angular stabilities, is a cornerstone of secure and reliable operation of any modern power system. Under-frequency load shedding (UFLS) is a classic and commonly accepted measure used in $\mathrm{AC}$ power systems to counteract a potential frequency collapse following a 
serious loss-of-generation incidents and instant imbalance between generated and consumed power. The UFLS is typically triggered when the activation of available frequency reserves does not provide a sufficient frequency stabilization. UFLS is usually defined by a list of loads with matching frequency thresholds which are disconnected from the grid by frequency relays when the grid frequency reaches any of the predetermined thresholds in the list. The loads disconnected by UFLS are typically the whole MV side/-s of a HV/MV substation/-s [7].

The importance of the frequency stability for an AC power system increases with decreasing power system size due to decreasing system inertia and increasing ROCOF during loss-of-generation incidents. Equation (1) which is a form of swing equation [8] clearly shows that the change in system frequency $\mathrm{d} \omega / \mathrm{dt}$ is reverse proportional to the total system inertia $\mathrm{H}_{\text {tot }}$ in MWs, so that decreasing inertia level will lead to a faster fall in frequency for the same power imbalance $\Delta \mathrm{P}$ :

$$
\frac{\mathrm{d} \omega}{\mathrm{dt}}=\Delta \mathrm{P} \frac{\omega_{\mathrm{syn}}}{2 \mathrm{H}_{\mathrm{tot}}}
$$

The importance of UFLS and its response time increases with decreasing power system size and inertia as the UFLS frequency thresholds are reached faster in smaller AC power systems with less inertia. An introduction of faster UFLS triggering would therefore be beneficial especially for AC systems of medium and small sizes.

Equation (1) clearly states that in order to improve $\mathrm{d} \omega / \mathrm{dt}$ one can either increase the available system inertia $\mathrm{H}_{\text {tot }}$ - by adding more synchronous machines (as for example synchronous condensers) or introducing synthetic inertia-or reducing the $\Delta \mathrm{P}$ by improving the existing UFLS algorithms.

Traditional UFLS schemes-triggered solely by a frequency threshold - can be enhanced by more sophisticated UFLS schemes and concepts proposed and described in the literature [9-13]. A semi-adaptive UFLS scheme can use a triggering method utilizing static frequency and ROCOF thresholds instead of a frequency-only approach. An adaptive UFLS scheme can adopt triggering methods employing a dynamic combination of frequency and ROCOF. Another type of dynamic UFLS schemes use algorithms including calculating the system inertia values or the total power imbalance of the system and use these for load shedding triggering together with frequency and ROCOF threshold values [11,12] or even bus voltage threshold values [13]. Some of the adaptive schemes described by the literature propose to use artificial intelligence or neural networks in order to automatically determine the number of loads to be shed for each disturbance, but it is unclear how to educate the neural network without compromising the safety and stability of a real power system [14]. All of the proposed UFLS schemes use frequency measurements in one or another manner.

Despite the advantages of the adaptive approaches over the classic one, the disadvantages of the adaptive UFLS schemes are well known and described [15]. A still ongoing search for new methods or concepts for UFLS is explained by the complexity of using Equation (1) in adaptive approaches due to the complexity of a real power system with many generators, each with own moment of inertia. The frequency in a multi-machine power system becomes a local parameter during the transient power imbalance oscillations and the Equation (1) is then describing the behavior of each generator separately. As a result, to estimate the disturbance $\Delta \mathrm{P}$, knowledge of the frequencies and inertia of many generators in the power system is required. This fact indicates that a predictive approach to UFLS, as anticipated in [15], could be the next step in the development of UFLS. A search for improved UFLS approach for low-inertia power systems is the main motivation for authors of this paper and therefore a novel type of a predictive LS algorithm will be presented here.

In order to assess the efficiency of newly proposed UFLS schemes, dynamic simulations on standard test power system models, as for example IEEE XX bus standard test power systems, are usually executed and the results are investigated. The authors of this paper will follow another approach and will test the proposed LS approach through executing dynamic simulations on a specific model depicting the Baltic power system. 
This not only due to the origin of the authors-living and working in the Baltics—but also due to the expected rapid shift towards the renewable energy generation also in the Baltic power system due to the previously mentioned EU regulations [2].

Power transmission grid of the Baltic states is a meshed, interconnected $330 \mathrm{kV}$ grid with a peak load of ca. $4000 \mathrm{MW}$ [16]. It has a strong synchronous interconnection with the Unified Power System of Russia (UPS) synchronous power system and has asynchronous HVDC connections to both Finland, Sweden and Poland, see Figure 1. The maximum exchange capacity of all interconnections to the Baltics is around $4700 \mathrm{MW}$ [17], which makes it theoretically possible to supply the peak load of Baltic power grid with imports alone. Main generation assets in the Baltic power grid comprise of thermal oil-shale and wind power generation in Estonia, large river hydro power plants plus a major gas-fired power plant (Riga TEC2) in Latvia and a combination of wind power, small/medium sized CHPs, a major pump-storage and a major gas-fired power plant in Lithuania. Baltic power grid is heavily relying on imported power with the total import comprising in $201947,6 \%$ of the total consumption, with largest net power exporters to the Baltics in 2019 being Belarus, Finland and Sweden [18].

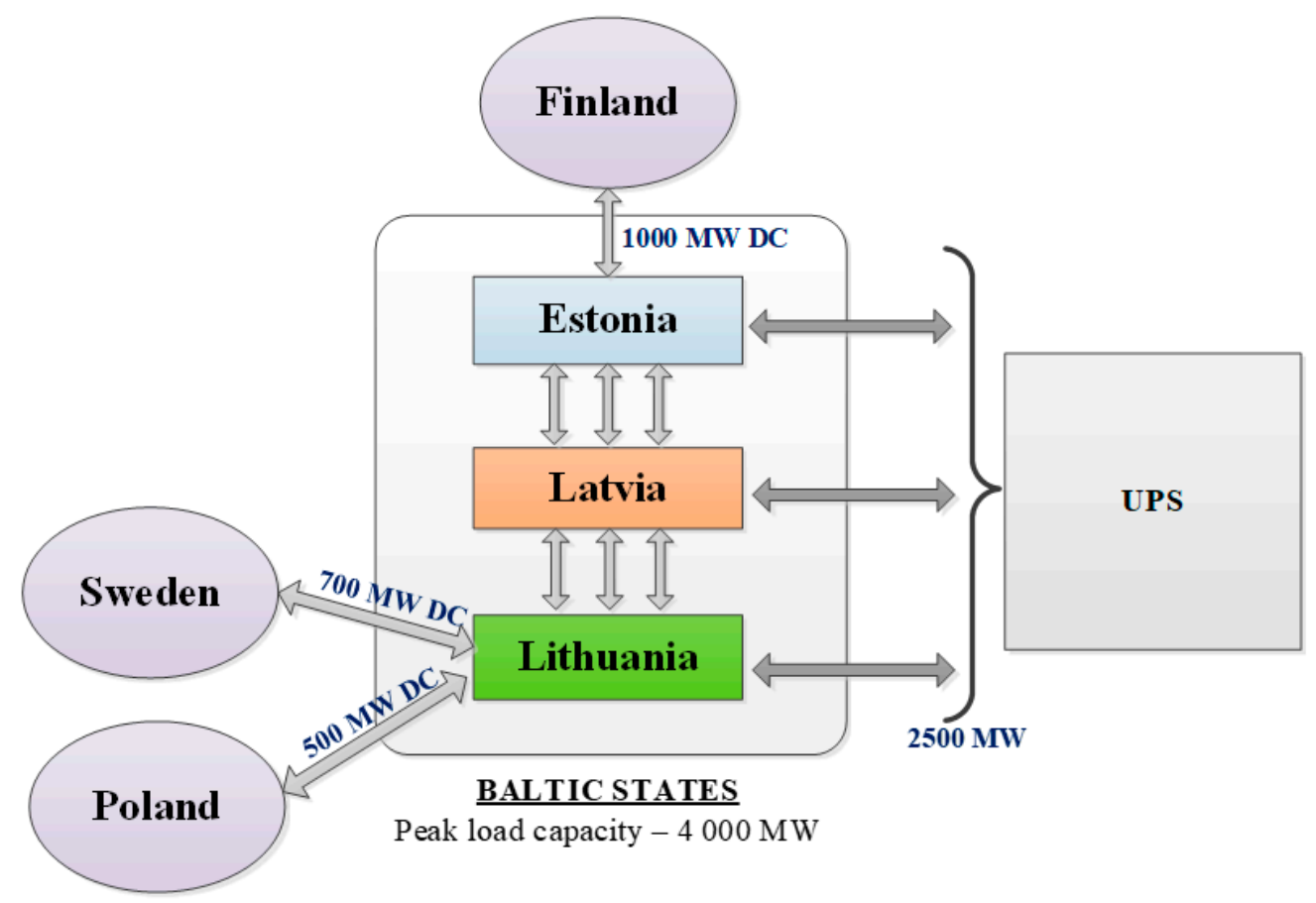

Figure 1. Schematic power system interconnection of the Baltic states.

The interconnection with UPS today provides the Baltic power system with vast frequency and inertia reserves. Frequency stability is not an issue in today's situation due to the size of the UPS synchronous power system. A political decision has been taken to desynchronize the Baltic states from the UPS power system and to synchronously connect it with the European Network of Transmission System Operators (ENTSO-E) power grid in 2025 [19]. Baltic and the UPS power systems are interconnected with nine $330 \mathrm{kV}$ transmission lines with the total thermal capacity of ca. $9000 \mathrm{MW}$ and a nominal transmission capacity of ca. $2500 \mathrm{MW}$. The upcoming synchronous connection between the Baltic and the ENTSO-E power systems is to succeed through a single double-circuit $400 \mathrm{kV}$ synchronous interconnection on the border Lithuania-Poland with thermal capacity of ca. 2000 MW [17]. Planned or unplanned outages of this interconnection will result in the operation of Baltic states' power grid in an island mode. During this mode of operation the Baltic power system is only to rely on its own inertia reserves which are radically lower than today's available inertia of the UPS power grid. The island mode of operation is to introduce major challenges to the frequency stability of the Baltic power grid. 
Another development to impact the inertia level of the Baltic power system is the expected rise in intermittent non-synchronous renewable generation capacity. Around $4000 \mathrm{MW}$ of wind generation capacity is planned in the Baltic states up to year 2034 according to [20]. Separate national renewable energy targets in the scope of the EU 2030 Climate \& Energy Framework [2] indicate sharp rise of share of renewable generation in Estonia and Lithuania, while Latvia is already close to fulfilling 2030 renewable electricity targets due to large existing hydropower generation capacity [21-23]. Wind power generators are non-synchronous so they do not contribute to the system inertia. This implies that the total inertia level of the Baltic power system is expected to decline. It also expected that due to the rise of the share of intermittent generation and the subsequent volatility of the power prices, the operation of the synchronous generators is to be more volatile, with more start-and-stop cycles [24]. This means also volatility in the level of the total inertia of the power system.

To mitigate these developments and to safeguard frequency stability of the Baltic power grid Baltic TSOs have agreed to make investments in three synchronous condensers (SC) rated ca. 305 MVA each—-totaling nine synchronous condensers planned in the Baltic power grid by 2025 [17].

Synchronous condenser technology is far from new: SC is a synchronous generator without a prime mover as a steam turbine and therefore it is not a source of active power in a classic manner. A SC has all qualities of a classic synchronous generator, similar design and behavior. SC provides a wide reactive power regulating envelope, large short-circuit current capabilities and inertia which can be additionally increased by means of installing a flywheel on the SC rotor shaft [25]. SC requires some small amounts of active power for its operation. Due to their qualities SC have become increasingly popular again due to a sharp increase in decommissioning of synchronous generation (largely fossil) and in commissioning of non-synchronous renewable generation [26]. SC have become a powerful tool to meet challenges caused by increasing penetration of the grid by non-synchronous renewables, particularly reduction of the system inertia and the grid short-circuit current capabilities.

Summarizing the results of publications on frequency stability of power system with a significant share of renewable energy, we can note the following:

(1) The importance of the frequency stability for an AC power system increases with decreasing power system size due to decreasing system inertia and increasing rate of change of frequency (ROCOF) during loss-of-generation incidents;

(2) Synchronous condenser technology can be used to increase the system inertia and simplify the solution to the frequency control problem. In the event of a loss of large generating capacities, the use of SC makes it easier to solve the task of frequency control, but the problem of emergency frequency control remains to be acute;

(3) Attempts to improve the efficiency of UFLS schemes have until now been based on the use of ROCOF in one or another way. However, to the best of our knowledge, there are no studies aimed at improving UFLS based on the monitoring the SC response in transient conditions.

This article will present an innovative approach for a new adaptive UFLS method (main contribution of the article). This method is based on the combined simultaneous use of synchronous condensers and their active power control system. Unlike the known adaptive methods, the new method disconnects the load in the amount which is selected depending on the results of measuring not the ROCOF but the active power injections of synchronous condensers. The use of the proposed new parameter eliminates the problems of fast and accurate measuring the rate of change in frequency as also discussed in the next chapter. The remaining part is organized as follow: first theory, method and the principles of the proposed approach are described, then the case studies are portrayed, finally the discussion is conducted and the conclusions are made. 


\section{Materials and Methods}

\subsection{Inertia and Inertial Response}

Any power system under consideration includes following elements: synchronous generators, synchronous condensers, load with electric motors, renewable energy sources and high-voltage grid tie lines.

An unexpected disconnection of a large generator in the power system causes a transition to a new state-in particular, the rotation frequency of synchronous generators, synchronous condensers and motors is subject to change (decreases). In the process of decelerating of rotating masses of the elements of the power system, the kinetic energy accumulated in them is transformed into electric energy and injected into the electrical network. As result of this injection (inertial response) the balance of generated and consumed electrical energy is maintained even during the transient process. Within a few seconds delay after disturbance, generator's governors, in response to a decrease in frequency, start to react on the frequency decline trying to restore the frequency rated value (primary frequency control). Additionally, diminishing of the frequency causes a decrease in the power consumption of the frequency dependent load. However, the initial period of the considered transient process is mainly determined by the disconnected generator with active power $\Delta \mathrm{P}$ at the beginning of the process and the inertia of the system. In such case the impact of primary frequency control and the decrease in the power consumption can be neglected. Consequently, we can assert that the volume of the disconnected power $\Delta \mathrm{P}$ at the very beginning of the process prior to primary frequency control is compensated by the injection of the active power by each element of the power system possessing inertia:

$$
\Delta \mathrm{P}=\sum_{\mathrm{a}=1}^{\mathrm{S}} \Delta \mathrm{P}_{\mathrm{SC} \_\mathrm{a}}+\sum_{\mathrm{b}=1}^{\mathrm{G}} \Delta \mathrm{P}_{\mathrm{G}_{-} \mathrm{b}}+\sum_{\mathrm{c}=1}^{\mathrm{L}} \Delta \mathrm{P}_{\mathrm{L}_{-} \mathrm{c}}, \forall \mathrm{a} \in \mathrm{S}, \forall \mathrm{b} \in \mathrm{G}, \forall \mathrm{c} \in \mathrm{L}
$$

where $\Delta \mathrm{P}_{\mathrm{SC}_{-} \mathrm{a}}, \Delta \mathrm{P}_{\mathrm{G}_{-} \mathrm{b}}$ and $\Delta \mathrm{P}_{\mathrm{L}_{-} \mathrm{c}}$ are active power injections of every synchronous condenser, synchronous generator and frequency dependent load (for example electric motors) present in the power grid; where S, G, L are the total numbers of synchronous condensers, synchronous generators and frequency dependent loads in the power grid. To stop the change in frequency, it is enough to restore the balance of generation and consumption by disconnecting, for example, a load equal to $\Delta \mathrm{P}$. Estimates of the volume of this load can be carried out on the basis of measuring all $\Delta \mathrm{P}^{\prime} \mathrm{s}$ included in Equation (2). However, in real power systems, due to the large number of elements, this path is unacceptable. The problem can be simplified by assuming that Equation (2) can be represented as:

$$
\Delta \mathrm{P}=\mathrm{K}_{\mathrm{r}} * \sum_{\mathrm{a}=1}^{\mathrm{S}} \Delta \mathrm{P}_{\mathrm{SC} \_\mathrm{a}}
$$

where $\mathrm{K}_{\mathrm{r}}=\frac{\sum_{\mathrm{b}=1}^{\mathrm{G}} \Delta \mathrm{P}_{\mathrm{G}_{\_} \mathrm{b}}+\sum_{\mathrm{c}=1}^{\mathrm{L}} \Delta \mathrm{P}_{\mathrm{L}_{-} \mathrm{c}}}{\sum_{\mathrm{a}=1}^{\mathrm{S}} \Delta \mathrm{P}_{\mathrm{SC} \mathrm{a}}}+1$.

If the coefficient $\mathrm{K}_{\mathrm{r}}$ is known, to estimate $\Delta \mathrm{P}$ it is sufficient to measure the power injections of all synchronous condensers $\sum \Delta \mathrm{P}_{\mathrm{SC}}$. In real life, the coefficient $\mathrm{K}_{\mathrm{r}}$ is not a constant value, it depends on the operating mode of the power system, its topology and also of the total system inertia level. However, in any case, we can assert that the measured $\sum \Delta \mathrm{P}_{\mathrm{SC}}$ can be taken as the basis for disconnecting/shedding the load for frequency stabilization. This load shed must be in a volume not less than $\sum \Delta \mathrm{P}_{\mathrm{SC}}$. Such disconnection, as will be shown below, can significantly increase the efficiency of systems where the main source of inertia are synchronous condensers. Equation (3) will give an opportunity to rapidly predict the fall in the system frequency and therefore form the basis of the decision to initiate a fast triggering of the proposed LS scheme. Monitoring of SCs only is achievable in practice and can be used as a basis for power imbalance and system frequency prediction. The implementation of such a concept would require usage of a Wide Area Measurement System and dedicated measurement units/terminals. 


\subsection{Classic/Static UFLS and Its Challenges}

UFLS automated systems are used to rescue the power systems facing extreme disturbances to avoid system collapse. In event of sudden loss of generation, a power mismatch lead to frequency decline. In case the primary frequency regulation does not respond quickly enough or in the absence of power reserve, the UFLS sheds a certain amount of load, attempting to prevent frequency drop below the lowest acceptable limit. A classical UFLS has several steps of load disconnection and frequency thresholds and the amount of load disconnected for each step is predefined but may differ from system to system depending on the system specifics. The main disadvantage of such "static" UFLS schemes is their inability to adapt fixed thresholds and the amount of load to be shed by each step to continuously varying load/generation profiles and to severity of power imbalance. These deficiencies may result in late response or excessive load shedding. It is a common understanding that for the load-shedding to be effective it should be activated as quickly as possible and simultaneously it should be resilient to small disturbances so that no excessive load is shed [9].

Several adaptive, response-based UFLS schemes were mentioned earlier and some are also proposed in [27-30] to overcome the deficiencies of the static UFLS. Even probabilistic approaches are proposed for power systems where some loads are not crucial and are allowed to be shed in order to maintain the feed of critical loads [31]. The majority of adaptive UFLS estimate the initial imbalance of power $\Delta \mathrm{P}$ and then redistributes the total power deficit among several load shedding steps. The total power imbalance could be estimated from Equation (1) when ROCOF of the system is known/measured immediately after disturbance. The problem is that in multi-machine system generators might oscillate at different rates and, therefore, frequency gradient is not homogeneous at different nodes of the system. The concept of frequency of center of inertia (COI) $f_{\mathrm{COI}}$ was proposed to avoid this challenge. System with $\mathrm{n}$ generators is represented by equivalent COI generator and swing equation takes the form of Equation (4) where inertia constants $\mathrm{H}_{\mathrm{i}}$ are in a common system base $\mathrm{S}_{\text {base }}$ and $\mathrm{f}_{\mathrm{COI} \text {,p.u. }}$ is the system frequency divided by the system nominal frequency. Calculation of the COI necessitate the online knowledge of all generators inertia which is not a trivial task, especially when RES inertia uncertainty is considered:

$$
\frac{\mathrm{df}_{\mathrm{COI}, \mathrm{p} . \mathrm{u}}}{\mathrm{dt}}=\frac{\Delta \mathrm{P}_{\mathrm{COI}, \mathrm{p} . \mathrm{u}} * \mathrm{f}_{\mathrm{COI}, \mathrm{p} . \mathrm{u} .}}{2 \sum_{\mathrm{i}=1}^{\mathrm{n}} \mathrm{H}_{\mathrm{i}}\left(\frac{\mathrm{S}_{\text {rate, } \mathrm{i}}}{S_{\text {base }}}\right)},
$$

A comprehensive overview of the ROCOF-based power imbalance estimation-related problems is given in [32]. It was concluded that besides the inertia, several additional factors may influence the estimation, namely, the initial system loading and the load voltage characteristics need to be taken into account. Ignoring these factors along with some frequency gradient measurement issues [33] may lead to significant inaccuracies in power imbalance calculation and, therefore, may negatively affect UFLS performance.

\subsection{The Concept}

Earlier simulations conducted for the Baltic grid in island mode [34] have shown that after shortfall of a major generation unit a ROCOF of $0.75 \mathrm{~Hz} / \mathrm{s}(0-500 \mathrm{~ms})$ is observed and the typical classic first UFLS threshold of $49 \mathrm{~Hz}$ is reached in approx. $1.75 \mathrm{~s}$ from the moment of the contingency. That means that if an alternative UFLS method is to bring added value to the Baltic power grid it should provide triggering considerably faster than $1.75 \mathrm{~s}$. [35] states that a fast response for frequency stabilization should be activated faster than $800 \mathrm{~ms}$ in situations with ROCOF of around $1 \mathrm{~Hz} / \mathrm{s}$.

We would like to propose a principle of much faster triggering of LS than that of the conventional UFLS- a principle which allows to trigger (not to be confused with activate) LS up to $100 \mathrm{~ms}$ from the moment of the contingency without usage of either frequency or ROCOF measurements, activate the LS considerably faster than conventional UFLS and is based on a predictive approach. The principle is based on the monitoring of the active power injections of the SCs. Our hypothesis is following: active power injection 
of a SC in an AC power system contains information on the instantaneous shortfall of a major generation unit and the expected fall in frequency. SC active power injections can therefore be used as a set off for rapid LS activation. Execution of such a rapid scheme of LS substantially reduces the frequency fall and the value of frequency nadir, thus greatly reducing the risk of frequency limit violation in the given power grid. The schematic representation of the proposed LS principle is seen in Figure 2.

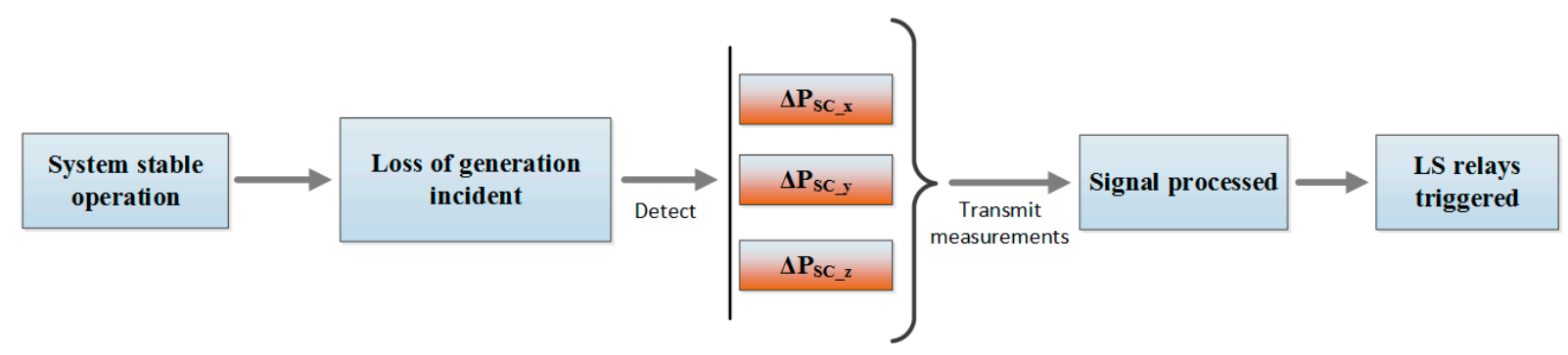

Figure 2. Schematic of the proposed LS principle.

To prove the concept and the hypothesis we will perform two sets of power grid dynamic simulation case studies based on two different Baltic power grid models derived from models found in [34] and presenting a range of scenarios for the Baltic power system: from today's situation with little non-synchronous renewable generation of considerable size to a scenario with non-synchronous renewable generation supplying a major part of the electricity demand. Two different and independent sets of test cases on two different models depicting the Baltic power system in different simulation environments-Siemens PSSE ver. 34 and ETAP ver. 12.5 [36,37] — are executed in order to cross-check the performance of our proposed LS concept and to prove its efficiency to keep the frequency within the operational limits of the power grid.

\section{Case Study}

\subsection{Methodology and Results. Test Case Set No. 1}

The first case study set will be done on a model of the Baltic power grid in island mode already presented in [34] and now enhanced with adding a set of synchronous condensers (SC): 3 SCs rated ca. 305 MVA each added to the busbar of every Baltic country-totaling $9 \mathrm{SC}$. The SC are of turbogenerator-type with active power set to 0 , each having an inertia constant of $\mathrm{H}=6.23 \mathrm{~s}$, providing a total inertia of $17101 \mathrm{MWs}$. The other dynamic characteristics of the SCs for the model are provided by [17]. Additionally, three tie lines between Latvian and Lithuanian zones are now present to depict the realities of the Baltic power system The rest of model characteristics are identical to that in [34]. A diagram of the modelled grid can be seen in Figure 3. An overview of the system parameters in the different modelled scenarios is seen in Table 1.

Table 1. Grid model parameters for different modelled scenarios, test case set 1, MW/MWs in italic.

\begin{tabular}{|c|c|c|c|c|}
\hline & \multicolumn{4}{|c|}{ Scenario } \\
\hline & A & B & $\mathrm{C}$ & $\mathbf{D}$ \\
\hline Total generation before disruption & 2567 & 2548 & 2623 & 2686 \\
\hline -of it renewable non-synchronous & 100 & 700 & 1500 & 2500 \\
\hline Total load & 3700 & 3700 & 3700 & 3700 \\
\hline Total import & 1700 & 1700 & 1600 & 1530 \\
\hline Total export & 500 & 500 & 500 & 500 \\
\hline Total post-contingency system inertia $\mathrm{H}_{\text {tot_post }}$ & 29,779 & 36,739 & 24,768 & 18,091 \\
\hline Gen. loss event & TEC2, $800 \mathrm{MW}$ & HVDC, $700 \mathrm{MW}$ & HVDC, $700 \mathrm{MW}$ & HVDC, $700 \mathrm{MW}$ \\
\hline
\end{tabular}




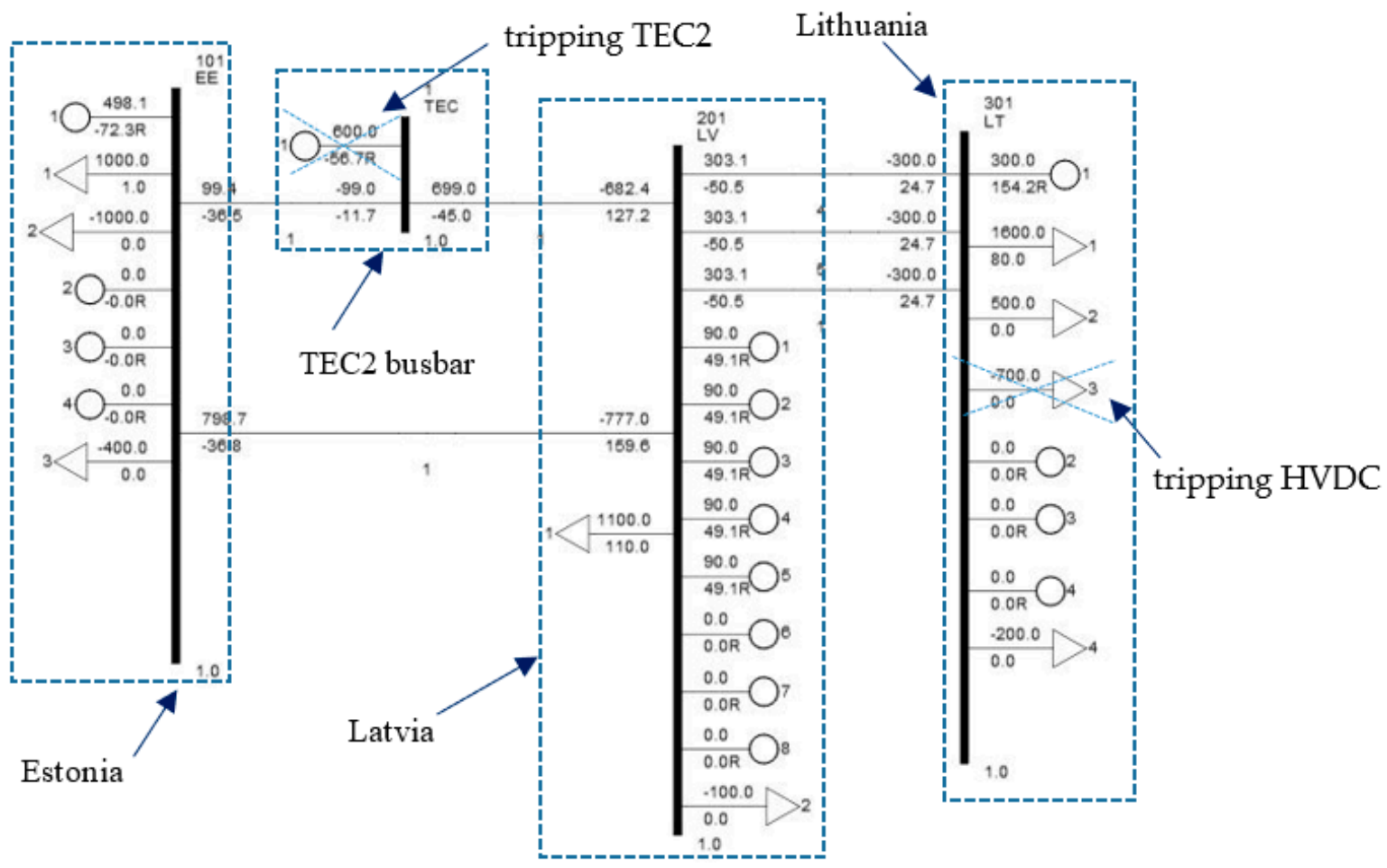

Figure 3. Schematic diagram of the modelled Baltic power grid for test case set No. 1.

For all scenarios of the first test case set the most severe disturbance available will be modelled: tripping of TEC2 with $800 \mathrm{MW}$ or HVDC import cable with $700 \mathrm{MW}$. Scenarios $\mathrm{B}, \mathrm{C}$ and $\mathrm{D}$ have an increasing wind power generation levels displacing the generation on the top of the merit-order, which for the Baltics is TEC2. This means the tripping of TEC2 with full power is not possible in the scenarios $B, C$ and D and therefore the tripping of the 700 MW HVDC cable becomes the largest incident. Active power injections of the SC on each country busbar will then be examined and used to draw the basics of the proposed LS concept. The total SC active power injections $\Delta \mathrm{P}_{\mathrm{SC}}$ will be monitored from $\mathrm{t} \geq 20 \mathrm{~ms}$ from the start of contingency, as $20 \mathrm{~ms}$ is one period for a $50 \mathrm{~Hz} \mathrm{AC}$ grid and measurement accuracy at $\Delta t$ under 1 period can be problematic due to the function principles of the voltage and current measurement units, as well as due to the sub-transient and transient electromagnetic processes in the rotor-stator pair of any synchronous generator. This will be the procedure for measuring $\Delta \mathrm{P}_{\mathrm{SC}}$ for the test case set No. 2 as well. For all scenarios of the first test case a separate simulation for cases with no LS, with conventional UFLS and with the proposed LS method will be executed in order to compare frequency responses. The parameters for the conventional UFLS for the test case set 1 are given by Table 2 with activation time delay of $0.17 \mathrm{~s}$ after threshold has been reached.

Table 2. Conventional UFLS parameters, test case set No. 1.

\begin{tabular}{ccccccc}
\hline & \multicolumn{7}{c}{ Load Shedding Step Number, $\mathbf{n}$} \\
\hline & $\mathbf{1}$ & $\mathbf{2}$ & $\mathbf{3}$ & $\mathbf{4}$ & $\mathbf{5}$ & $\mathbf{6}$ \\
\hline Freq. threshold, Hz & 48.8 & 48.6 & 48.4 & 48.2 & 48.0 & 47.8 \\
P $_{\text {load_UFL__n } \%} \%$ & 5.4 & 6.1 & 7.5 & 6.4 & 5.4 & 4.4 \\
\hline
\end{tabular}

Note that the implementation of a load shedding using the measured power injection value $\Delta \mathrm{P}_{\mathrm{SC}}$ can be realized in various ways. First, we present results corresponding to one of the simplest schemes (the second scheme will be described in Section 3.2): if a power injection $\Delta \mathrm{P}_{\mathrm{SC}}$ is detected and measured, then the load is disconnected according to the following algorithm: 
If $\Delta \mathrm{P}_{\mathrm{SC}}>\mathrm{P}_{\text {load_UFLS_1 }}$ AND If $\Delta \mathrm{P}_{\mathrm{SC}}<\left(\mathrm{P}_{\text {load_UFLS_1 }}+\mathrm{P}_{\text {load_UFLS_2 }}\right)$ then $\mathrm{P}_{\text {load_novel_LS }}=\mathrm{P}_{\text {load_UFLS_1 }}$
If $\Delta \mathrm{P}_{\mathrm{SC}}>\left(\mathrm{P}_{\text {load_UFLS_1 }}+\mathrm{P}_{\text {load_UfLS_2 }}\right)$ AND If $\Delta \mathrm{P}_{\mathrm{SC}}<\left(\mathrm{P}_{\text {load_UFLS_1 }}+\mathrm{P}_{\text {load_UFLS_2 }}+\mathrm{P}_{\text {load_UFL_3 }}\right)$ then $\mathrm{P}_{\text {load_novel_LS }}=\mathrm{P}_{\text {load_UFLS_2 }}$

where $P_{\text {load_UfLS_1 }}, P_{\text {load_UfLS_2 }}, \ldots$ are loads shed carried out by the corresponding step of conventional UFLS (see Table 2). $P_{\text {load_novel_LS }}$ is load shed cared out by the proposed LS method. The total load shed by conventional UFLS is the sum of all the relevant steps $P_{\text {load_UFLS }}=P_{\text {load_UFLS_1 }}+P_{\text {load_UFLS_2 }}+\ldots$

For each scenario the volume of load shed by the conventional and new methods is the same. Observance of this equality makes it easier to compare the efficiency of both compared LS schemes. The LS done with the proposed method is activated with time delay of no more than $0.4 \mathrm{~s}$ after the triggering of the scheme (up to $0.5 \mathrm{~s}$ after the disturbance itself).

\subsubsection{Scenario A}

An outage of TEC synchronous generation of $800 \mathrm{MW}$ is simulated at $t=5 \mathrm{~s}$ and the LS activated according to the proposed method. The active power response of SCs can be seen in Figure 4: the SCs in all three countries react instantly with the SC closest to outage location injecting more active power; at $\mathrm{t} \approx 5.5 \mathrm{~s}$ the drop of active power injections due to LS activation can be seen. Active power responses are scaled p.u. to the base MVA rating of 1200 MW. Figure 5 shows the frequency responses of all simulations within scenario A, frequency is scaled p.u. to the base of $50 \mathrm{~Hz}$.

In Figure 4 the instantaneous active power response of Estonian and Latvian SCs (red and green curves) being closest to the tripped generator reaches $54 \mathrm{MW}$ each, the response of the Lithuanian SC (blue curve) is around $32 \mathrm{MW}$ and it reacts on the disturbance much slower as being furthermost from the tripped generator in the model. The $\Delta \mathrm{P}_{\mathrm{SC}}=420 \mathrm{MW}$. Figure 5 shows that with conventional UFLS frequency falls to $48.7 \mathrm{~Hz}$ and with proposed LS method-to $48.85 \mathrm{~Hz}$.

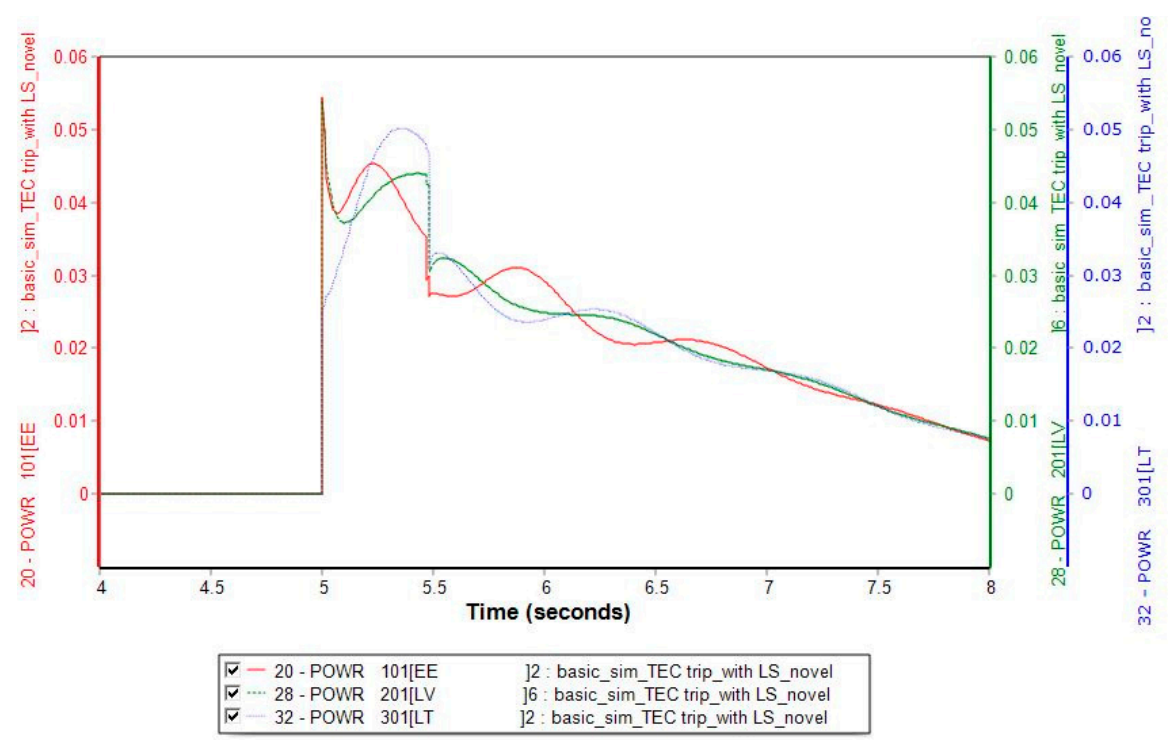

Figure 4. Active power injections of the SC, scenario A with novel LS method. 


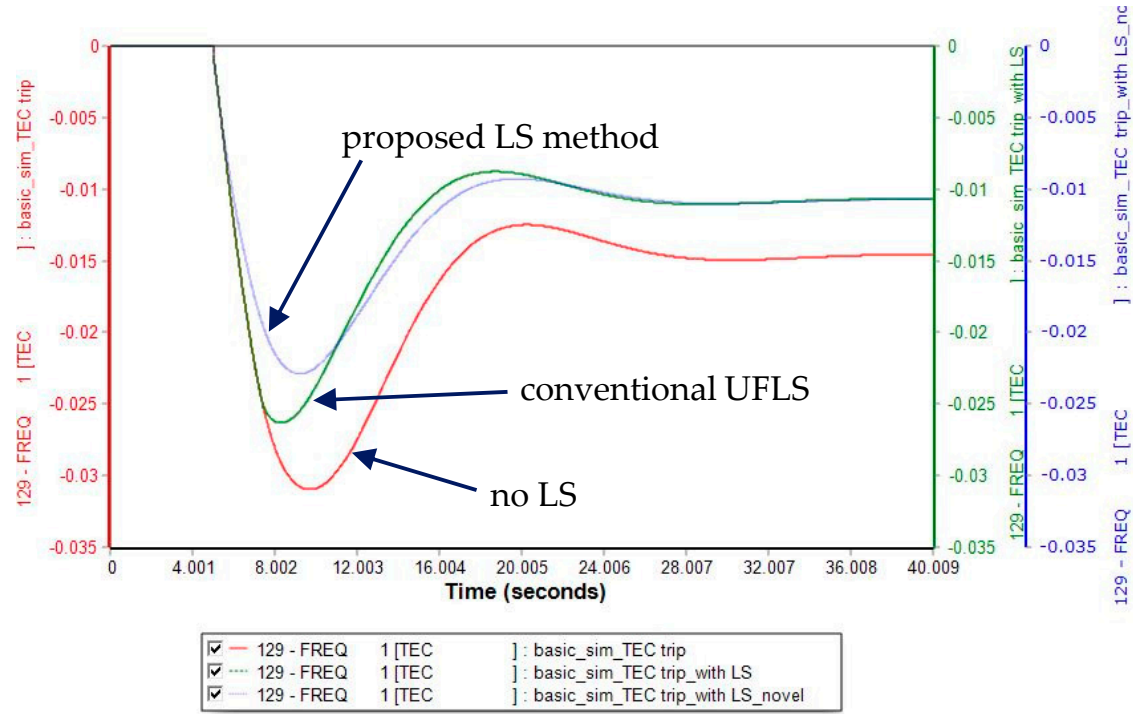

Figure 5. Frequency responses, scenario A.

\subsubsection{Scenario B}

An outage of HVDC import cable of $700 \mathrm{MW}$ is simulated at $\mathrm{t}=5 \mathrm{~s}$ and no conventional UFLS is activated due to insufficient fall in frequency. In the same way a simulation with the proposed LS method is conducted. The active power response of SCs can be seen in Figure 6: the SCs in all three countries react instantly with the SCs closest to outage location injecting more active power. Active power responses are scaled p.u. to the base MVA rating of 1200 MW. Figure 7 shows the frequency responses of both simulations within scenario B, frequency is scaled p.u. to the base of $50 \mathrm{~Hz}$.

In Figure 6 the instantaneous active power response of Estonian and Latvian SC (red and green curves) are $11 \mathrm{MW}$ and $46 \mathrm{MW}$, the response of the Lithuanian SC (blue curve) being closest to the tripped HVDC cable is around $89 \mathrm{MW}$. Estonian SC reacts on the disturbance much slower as being furthermost from the tripped HVDC cable in the model. The $\Delta \mathrm{P}_{\mathrm{SC}}=438 \mathrm{MW}$. Figure 7 shows that the frequency falls to $48.81 \mathrm{~Hz}$ und is not sufficient to activate the conventional UFLS; with the proposed LS method activated the frequency falls only to $49.1 \mathrm{~Hz}$.

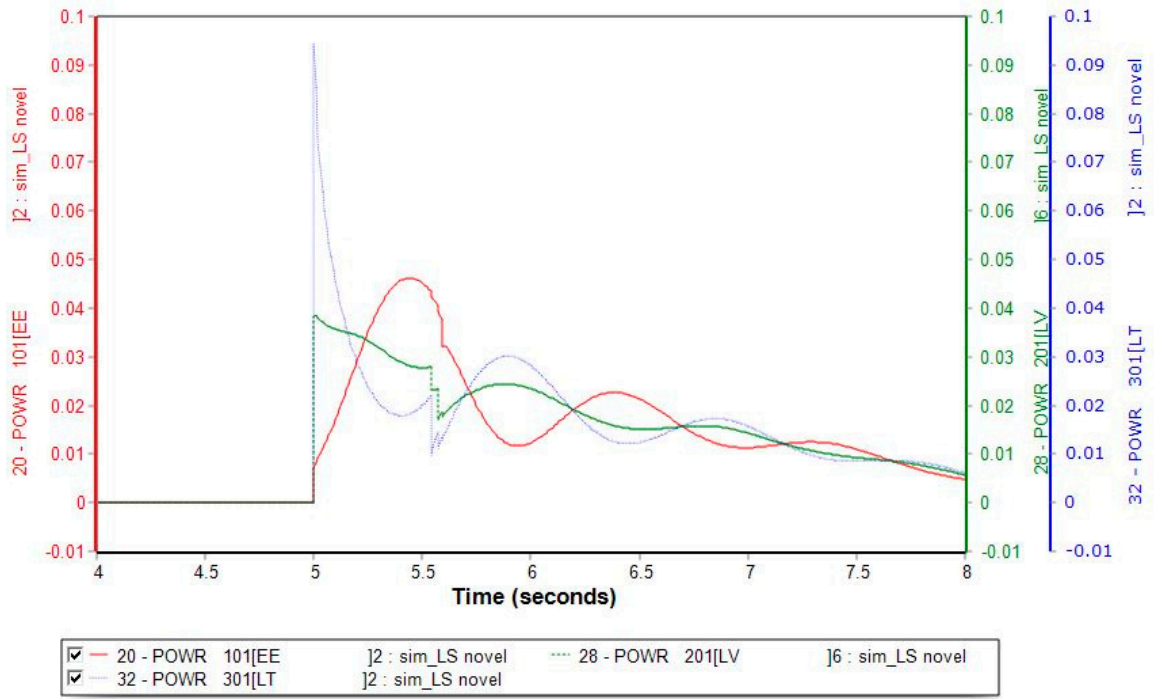

Figure 6. Active power injections of the SC, scenario B with novel LS method. 


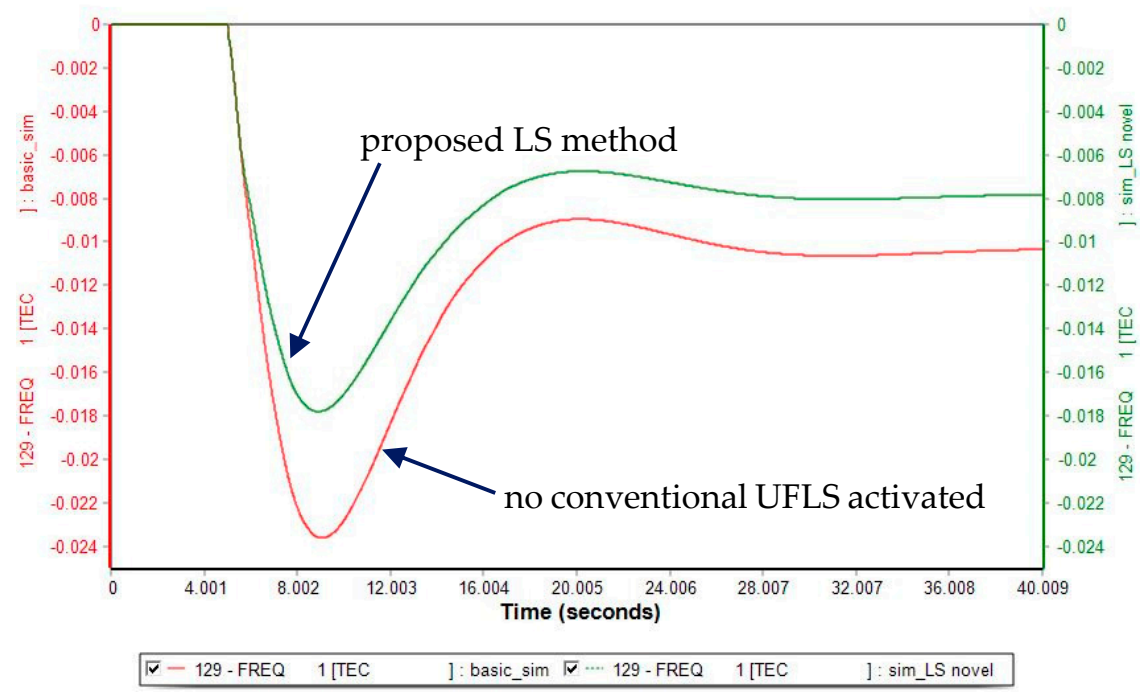

Figure 7. Frequency responses, scenario B.

The scenario B stands out from the other scenarios in the test case set by both a large amount of system inertia and a large amount of available spinning reserves, that also explains the fact that in this scenario the classical UFLS is not activated-the primary regulators of the synchronous generators limit the fall of the frequency. The scenario also shows a potential strength of the proposed LS method for high-inertia cases: it is activated and contributes to limit the fall in frequency also in cases when no conventional UFLS is expected to be activated.

\subsubsection{Scenario C}

An outage of HVDC import cable of $700 \mathrm{MW}$ is simulated at $\mathrm{t}=5 \mathrm{~s}$ and the LS activated according to the proposed method. The active power response of SCs can be seen in Figure 8: the SCs in all three countries react instantly with the SCs closest to outage location injecting more active power; at $\mathrm{t} \approx 5.5 \mathrm{~s}$ the drop of active power injections due to LS activation can be seen. Active power responses are scaled p.u. to the base MVA rating of 1200 MW. Figure 9 shows the frequency responses of all simulations within scenario C, frequency is scaled p.u. to the base of $50 \mathrm{~Hz}$.

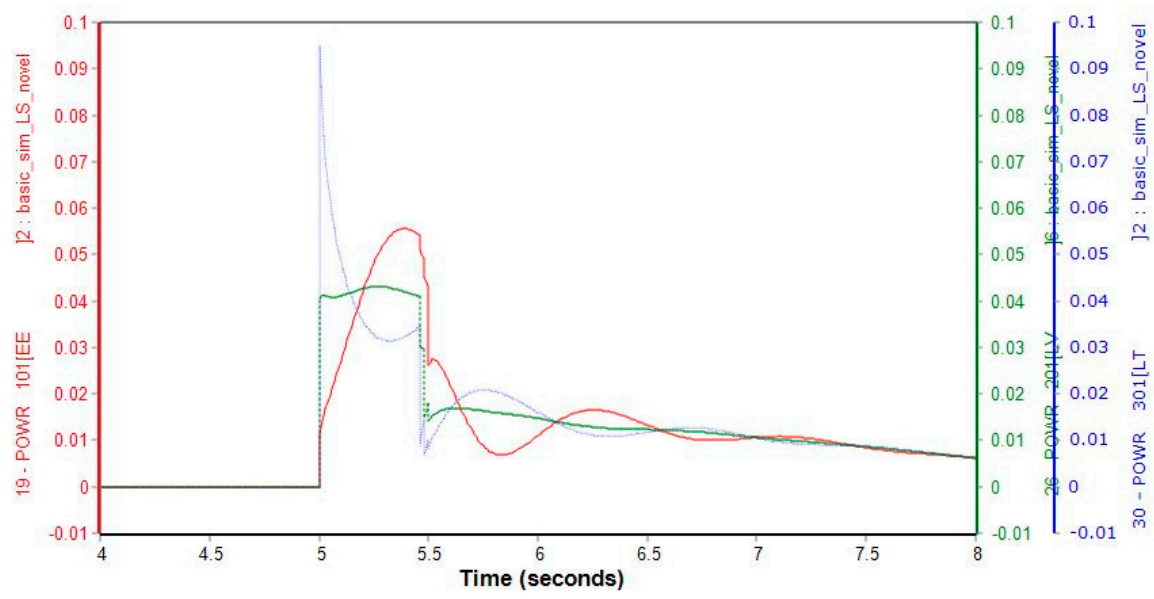

\begin{tabular}{|lll|}
\hline$\sqrt{V}-19-$ POWR & $101[\mathrm{EE}$ & ]2: basic_sim_LS_novel \\
$\sqrt{\nabla} \cdots 26$ - POWR & $201[\mathrm{LV}$ & ]6: basic_sim_LS_novel \\
$\mathbb{V}-30$ - POWR & $301[$ LT & ]2: basic_sim_LS_novel \\
\hline
\end{tabular}

Figure 8. Active power injections of the SC, scenario C with novel LS method. 


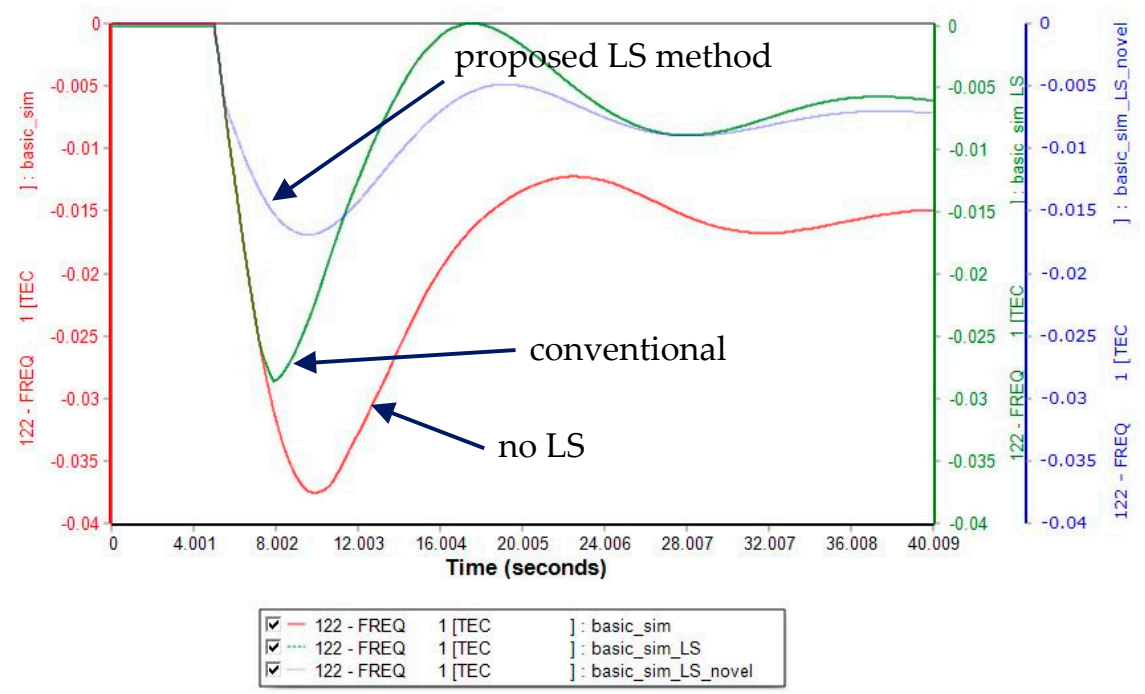

Figure 9. Frequency responses, scenario C.

In Figure 8 the instantaneous active power response of Estonian and Latvian SC (red and green curves) are $18 \mathrm{MW}$ and $49 \mathrm{MW}$ each, the response of the Lithuanian SC (blue curve) being closest to the tripped HVDC cable is around $91 \mathrm{MW}$. Estonian SC reacts on the disturbance much slower as being furthermost from the tripped HVDC cable in the model. $\Delta \mathrm{P}_{\mathrm{SC}}=475 \mathrm{MW}$. Figure 9 shows that with conventional UFLS frequency falls to $48.6 \mathrm{~Hz}$ and with proposed LS method-to $49.15 \mathrm{~Hz}$.

\subsubsection{Scenario D}

An outage of HVDC import cable of $700 \mathrm{MW}$ is simulated at $t=5 \mathrm{~s}$ and the LS activated according to the proposed LS method. The active power response of SCs can be seen in Figure 10: the SCs in all three countries react instantly with the SC closest to outage location injecting more active power; at $\mathrm{t} \approx 5.5 \mathrm{~s}$ the drop of active power injections due to LS activation can be seen. Active power responses are scaled p.u. to the base MVA rating of 1200 MW. Figure 11 shows the frequency responses of all simulations within scenario D, frequency is scaled p.u. to the base of $50 \mathrm{~Hz}$.

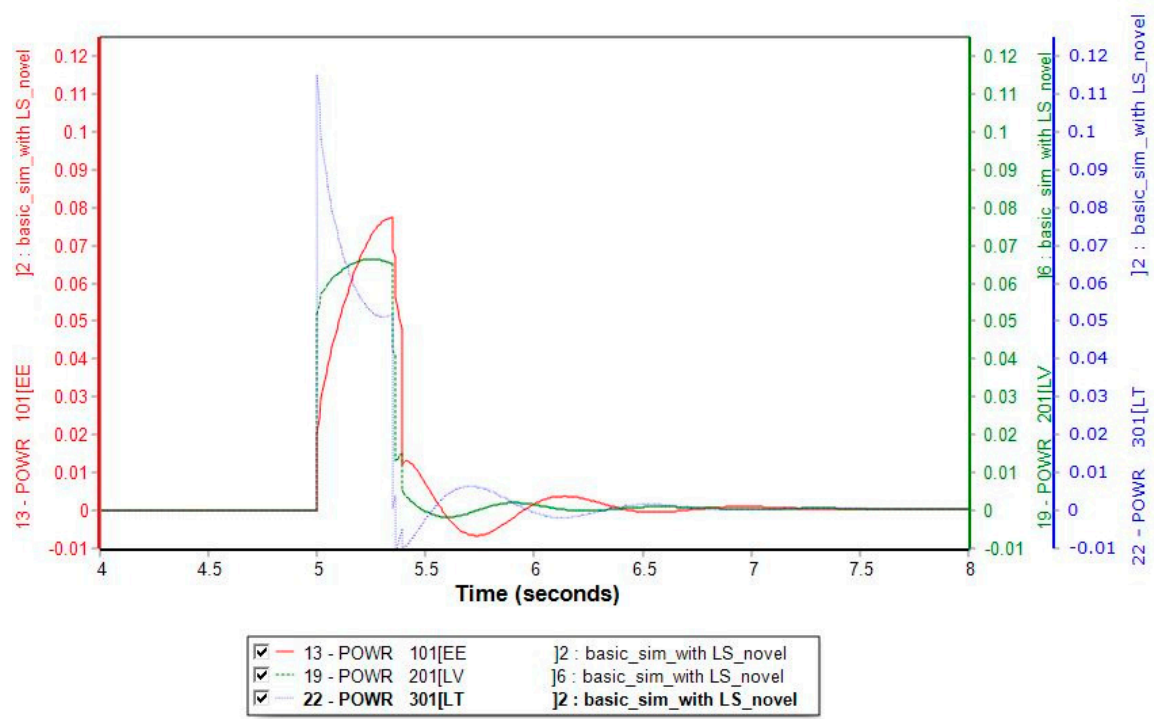

Figure 10. Active power injections of the SC, scenario D with novel LS method. 


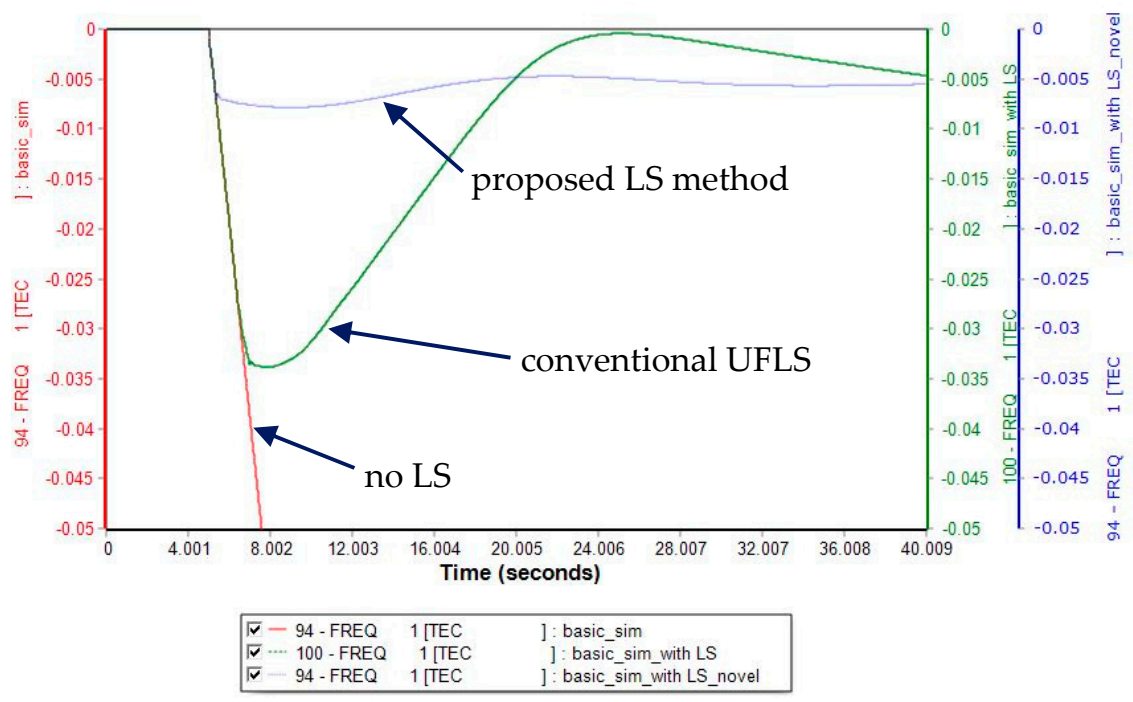

Figure 11. Frequency responses, scenario D.

In Figure 10 the instantaneous active power response of Estonian and Latvian SCs (red and green curves) are $36 \mathrm{MW}$ and $68 \mathrm{MW}$ each, the response of the Lithuanian SC (blue curve) being closest to the tripped HVDC cable is around $118 \mathrm{MW}$. Estonian SC reacts on the disturbance much slower as being furthermost from the tripped HVDC cable in the model. $\Delta \mathrm{P}_{\mathrm{SC}}=666 \mathrm{MW}$. Figure 11 shows that with conventional UFLS frequency falls to $48.3 \mathrm{~Hz}$ and with proposed LS method-to $49.6 \mathrm{~Hz}$.

The summary of results of test case set No. 1 can be seen in Table 3.

Table 3. Result summary, test case set No. 1.

\begin{tabular}{|c|c|c|c|c|}
\hline & \multicolumn{4}{|c|}{ Scenario } \\
\hline & A & B & $\mathrm{C}$ & D \\
\hline$\Delta \mathrm{P}_{\mathrm{SC}}, \mathrm{MW}$ & 420 & 438 & 475 & 666 \\
\hline$P_{\text {load UFLS }}, M W$ & 200 & 0 & 425.5 & 703 \\
\hline$P_{\text {load UFLS }} \%$ of total load & 5.4 & 0 & 11.5 & 19 \\
\hline Pload_novel_LS, MW & 200 & 200 & 425.5 & 703 \\
\hline Frequency nadir when UFLS does not activate (scenario B), Hz & - & 48.81 & - & - \\
\hline Frequency nadir conventional UFLS, $\mathrm{Hz}$ & 48.7 & - & 48.6 & 48.3 \\
\hline Frequency nadir novel LS method, $\mathrm{Hz}$ & 48.85 & 49.1 & 49.15 & 49.6 \\
\hline
\end{tabular}

\subsection{Methodology and Results. Test Case Set No. 2}

The second test case study set is also based on another model previously presented in [34]. The model (depicted in Figure 12) has a more detailed depiction of Latvian power system but depicts Estonian and Lithuanian power systems as grid equivalents-thus providing a different dynamic response to disturbances than the model in the test case set No. 1. The total rated power of the grid equivalents are 990 MVA for EE and 400 MVA for LT. This model also has 3 SC present (SC1, SC4 and SC6) rated at 305 MVA in the Latvian power grid as in the model of the test case set No. 1. The largest traditional generation plants are cogeneration plant CHP2 and hydro power plant HPP. Some of the traditional generation sources were replaced with wind parks (WTG2, WTG4 and WTG6) in order to imitate the increasing penetration of the non-synchronous renewable sources in the future. Despite this presence of the renewable sources the share of synchronous generation in the total load of scenarios A and B of the test case set are $91 \%$ which is exceptionally high for the Baltic power system today. This means the scenarios A and B represent historic rather than future situation. Scenarios $C$ and $D$ on the other hand give a realistic image of today's situation with a portion 
of synchronous generation in the total load around 50\%. An overview of the test case set scenario parameters in the different modelled scenarios is seen in Table 4.

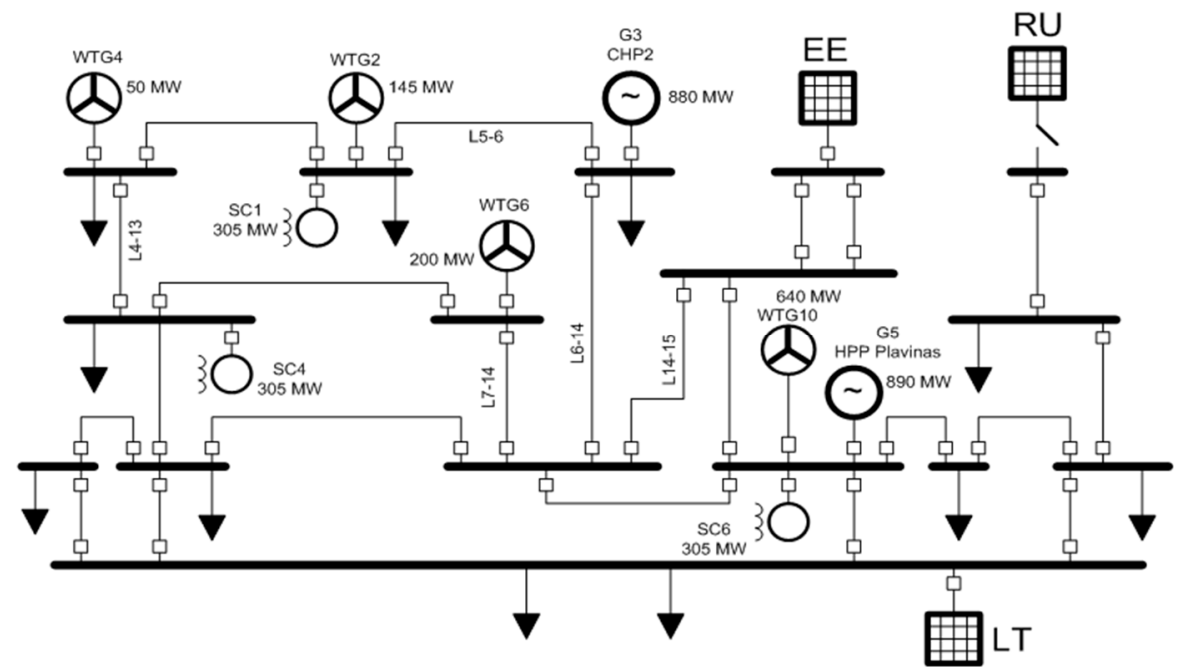

Figure 12. Schematic diagram of the modelled Baltic power grid for test case set No. 2.

Table 4. Grid element parameters for different modelled scenarios, test case set No. 2, MW/MWs in italic.

\begin{tabular}{ccccccccccc}
\hline Scenario & CHP2 & HPP & EE & LT & WTG2 & WTG4 & WTG6 & WTG10 & Gen. Loss Event & Total System Inertia \\
\hline A & 800 & 220 & 670 & 380 & 128 & 40 & 120 & x & EE & 15,760 \\
B & x & 800 & 990 & 400 & 128 & 40 & 120 & x & HPP & 12,150 \\
C & 800 & $x$ & 50 & 350 & 128 & 40 & 120 & 640 & CHP2 & 5790 \\
D & 800 & $\mathrm{x}$ & 50 & 350 & 128 & 40 & 120 & 640 & CHP2 & 12,148 \\
\hline
\end{tabular}

$\mathrm{x}=$ generation source not in operation.

Four scenarios (A-D) were simulated using ETAP 12.5 electrical software [37]. The goal of simulation was to explore the system frequency response under various loss-ofgeneration events. Total load of the Latvian grid is assumed to be ca. $2400 \mathrm{MW}$ for all cases. Approximately half of the consumption is covered by in-house generation capacity with the remaining power imported from EE and LT. The loss-of-generation events were simulated by disconnecting one of the major generation source. Operation mode with minimal system inertia is simulated in scenario C: CHP2, EE and LT generation sources inertia constants has been reduced to $\mathrm{H}=0.1 \mathrm{~s}$.

For the second set of tests, simulations were first done with conventional UFLS and then with the proposed LS method. Additionally, now we use a different scheme (compared to the one described in Section 3.1) for choosing the volume of the load to be disconnected. We assume that the volume of the load to be disconnected- $\mathrm{P}_{\text {load_novel_LS }}$ is proportional to the injection power $\triangle \mathrm{PSC}$ of all $\mathrm{SC}$ according to Equation (5):

$$
\mathrm{P}_{\text {load_novel_LS }}=\mathrm{K} * \Delta \mathrm{P}_{\mathrm{SC}},
$$

where $\mathrm{K}$ is the coefficient-which we wish to predict to be as close to the coefficient $\mathrm{K}_{\mathrm{r}}$ appearing in Equation (3). The parameters of conventional UFLS are given by the Table 5 with activation time delay of $0.3 \mathrm{~s}$ after threshold has been reached. The total amount of load shed by the conventional UFLS is $P_{\text {load_UFLS. }}$ 
Table 5. Conventional UFLS parameters, test case set No. 2.

\begin{tabular}{cccccccc}
\hline & \multicolumn{7}{c}{ Load Shedding Step Number, $\mathbf{n}$} \\
\hline & $\mathbf{1}$ & $\mathbf{2}$ & $\mathbf{3}$ & $\mathbf{4}$ & $\mathbf{5}$ & $\mathbf{6}$ \\
\hline Freq. threshold, $\mathrm{Hz}$ & 49.0 & 48.8 & 48.6 & 48.4 & 48.2 & 48.0 \\
P $_{\text {load_UFLS_n }} \%$ & 5 & 5 & 10 & 10 & 10 & 10 \\
\hline
\end{tabular}

The load shed with the novel LS method with time delay of $0.3 \mathrm{~s}$ after the disturbance. In cases where the amount of load shed by the novel LS method was not sufficient to limit the fall in frequency the conventional UFLS will kick in according to the thresholds in Table 5.

For each scenario of test case set No. 2 simulations with generation loss event at $t=$ $0.5 \mathrm{~s}$ were carried out: with conventional UFLS and with novel LS method with coefficient $\mathrm{K}=1$; for scenario $\mathrm{B}$ also simulations with coefficients $\mathrm{K}=2$ and $\mathrm{K}=3$ were executed to reach the best frequency result within the criteria of added value of the novel LS method. For simulations with the novel LS method the conventional UFLS scheme was still active and it contributed with additional shed load as we see in the scenarios B and D. The simulation results for all scenarios of the test case set No. 2 are given in Table 6. The frequency responses of the simulations of scenario B are given in the Figure 13.

Table 6. Result summary, test case set No. 2.

\begin{tabular}{|c|c|c|c|c|c|c|c|c|c|c|}
\hline \multirow{2}{*}{ Scenario } & \multirow{2}{*}{$\begin{array}{c}\Delta \mathbf{P}_{\text {gen_loss }} \\
\mathbf{M W}\end{array}$} & \multirow{2}{*}{$\begin{array}{l}\Delta \mathbf{P}_{\text {load_UFLS, }} \\
\quad \mathbf{M W}\end{array}$} & \multirow{2}{*}{$\begin{array}{l}\text { Conventional } \\
\text { UFLS } \mathrm{f}_{\min }, \mathrm{Hz}\end{array}$} & \multirow{2}{*}{$\begin{array}{l}\Delta \mathbf{P}_{\mathrm{SC}} \\
\mathbf{M W}\end{array}$} & \multicolumn{2}{|c|}{$\begin{array}{c}\text { Novel Approach LS } \\
\text { with } K=1 \\
\text { + Additional Load } \\
\text { Shed by Conv. UFLS }\end{array}$} & \multicolumn{2}{|c|}{$\begin{array}{c}\text { Novel Approach LS } \\
\text { with } K=2 \\
+ \text { Additional Load } \\
\text { Shed by Conv. UFLS }\end{array}$} & \multicolumn{2}{|c|}{$\begin{array}{c}\text { Novel Approach LS } \\
\text { with } \mathrm{K}=3 \\
\text { + Additional Load } \\
\text { Shed by Conv. UFLS }\end{array}$} \\
\hline & & & & & $\mathrm{f}_{\min }, \mathrm{Hz}$ & $\begin{array}{l}\text { Add. } \\
\text { Conv. } \\
\text { UFLS, } \\
\text { MW }\end{array}$ & $\mathrm{f}_{\min }, \mathrm{Hz}$ & $\begin{array}{l}\text { Add. } \\
\text { Conv. } \\
\text { UFLS, } \\
\text { MW }\end{array}$ & $\mathrm{f}_{\min }, \mathrm{Hz}$ & $\begin{array}{l}\text { Add. } \\
\text { Conv. } \\
\text { UFLS, } \\
\text { MW }\end{array}$ \\
\hline A & 670 & 120 & 48.9 & 150 & 49.06 & - & N/A & - & N/A & - \\
\hline B & 800 & 960 & 48.1 & 280 & 48.4 & 480 & 48.72 & 240 & 49.48 & - \\
\hline C & 800 & 720 & 48.29 & 800 & 49.4 & - & N/A & - & $\mathrm{N} / \mathrm{A}$ & - \\
\hline D & 800 & 480 & 48.45 & 330 & 48.9 & 120 & N/A & - & N/A & - \\
\hline
\end{tabular}

The scenarios in the test case set No. 2 were very diverse in terms of level of total system inertia and the parameters of the primary frequency control regulators. Scenario A had a high system inertia, which explains the minimal amount of $P_{\text {load_UfLS }}$ and $\Delta P_{S C}$. In scenario $B$ the system inertia was high but the power reserves of all of the remaining synchronous generators in the system were zero as the delivered active power of all remaining synchronous machines is equal to their rated apparent power: it is a rather unrealistic scenario but nevertheless included in the test case set. The amount load shed by conventional UFLS $P_{\text {load_UFLS }}$ in scenario B was exceptionally large and even with this large amount of load shed the frequency falls down to unacceptable value of $48.1 \mathrm{~Hz}$. This all due to the missing capability of the synchronous generators in the system to contribute with any active power. The response of the SC $\Delta \mathrm{P}_{\mathrm{SC}}$ in this scenario is also almost the double of that in scenario A with a similar level of system inertia. In the scenario B the coefficient $K$ had to be brought up to $K=3$ so that the $P_{\text {load_novel_LS }}$ could match the $P_{\text {load_UfLS }}$ for that scenario and prevent the fall of frequency to an unacceptable level. The proposed LS method shows clearly it's advantage in this particular scenario, but also highlights the fact that the novel approach LS coefficient $\mathrm{K}$ may have to possess a dynamic value proportional to the total system inertia. The determination of an algorithm for estimation of $\mathrm{K}$ for real system applications will be one of the topics of further research.

Scenarios $C$ and D have also shown that the proposed LS method significantly improves frequency response, especially for the low-inertia scenario C. 


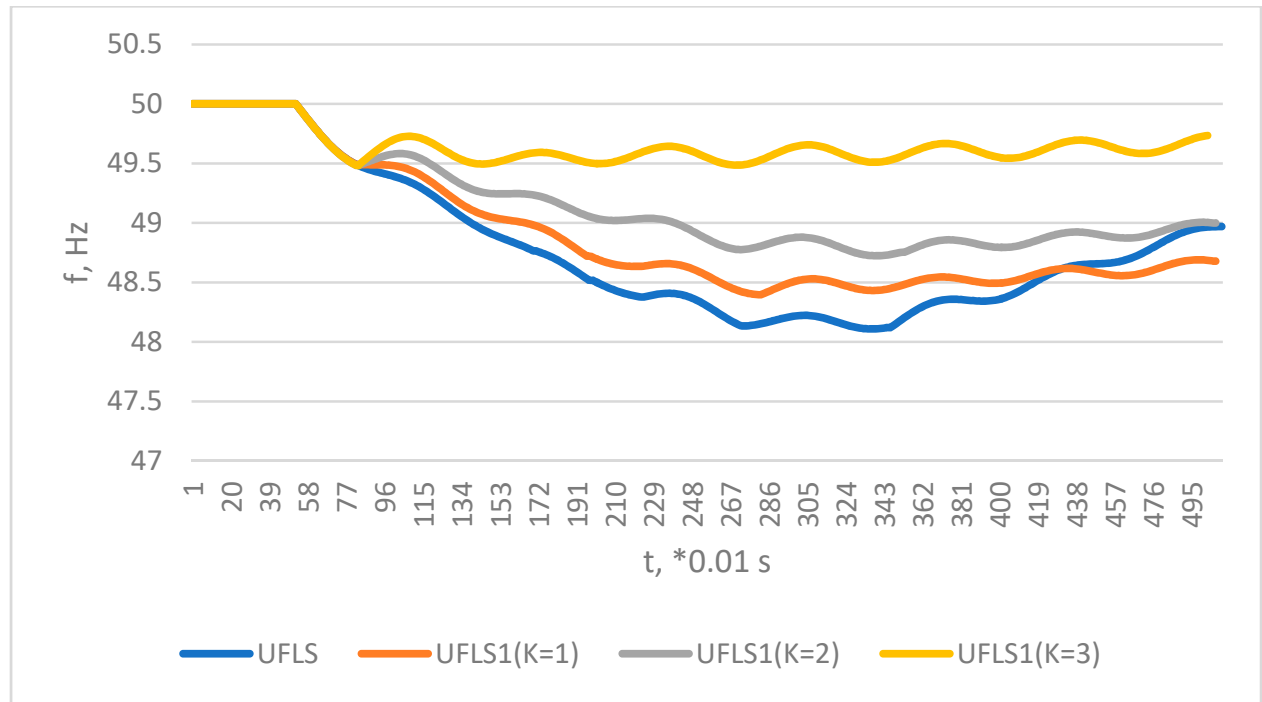

Figure 13. Frequency responses, scenario B.

\section{Discussion}

A principle of a novel LS method was introduced and two sets of case studies on assessment of the effect of the proposed approach were carried out. The case study sets were executed on two different and independent grid models and simulation software types. For every set and scenario the analysis of the response of SC was examined-active power injections of the SC during such incidents were observed and analyzed; for every set and scenario the effect of the proposed LS method was examined-the frequency responses for conventional UFLS and the novel LS approach were analyzed. Scenarios of the test cases had different system inertia levels, the topology of the grid was constant for every test case set.

Test case set No. 1-based on a simpler model topology—has shown that the response of the SC in case of contingency is related to the total system inertia level. For the highest inertia scenario (scenario B) no UFLS (either classic or novel) is triggered due to the vast contribution of the synchronous generators to the stabilization of frequency. The scenario A with 2nd highest system inertia a moderate response of the UFLS is registered and the novel LS method also provides only a modest contribution to the frequency stability.

Both low inertia scenarios (C and D) of the test case set No. 1 have shown that the proposed LS scheme provides a significantly improved post-contingency frequency response providing an effective measure for frequency stabilization. This verdict provides an important point - the proposed LS method is exceptionally suited for systems where the main source of inertia are synchronous condensers. The threshold of system inertia level at which the proposed LS method provides added value is the subject for further research on this topic.

Test case set No. 2-with a more detailed topology—shows similar results as the test case set No. 1: in high inertia scenarios the amount load shed decreases, which is logical due to the response of the synchronous generators in the system. Once again it is clear that the proposed LS method only provides a limited added value in frequency support in the high inertia scenarios.

As in the test case set No. 1, in the scenario with low system inertia (scenario C) the SC provide an intensive response to the contingency and the proposed LS method shows outstanding results in supporting the system frequency. We confirm once again that the contribution of the proposed LS method increases with decreasing system inertia. This also means that the practical implementation of the proposed LS method should possess a certain system inertia threshold at which the scheme is activated-leaving the ground clear for the conventional UFLS for system inertia levels larger than this threshold. The determination of the system inertia threshold is a matter of detailed simulations using practical topology of the grid the novel LS method is intended to be used for. 
The simulations altogether showed that SC actively counteract frequency disturbances caused by tripping of generation by injecting considerable amounts of active power into the grid. These injections are observed almost instantly, are of considerable size and are well measurable. Injections can be measured at $\mathrm{t} \geq 20 \mathrm{~ms}$ giving a principal basis for the triggering automation of the proposed LS method and proving the method to be perspective.

SC power injections are found to be mainly dependent on the total inertia amount in the system and on the amount of available spinning reserves. This implies that for the proposed LS method the fact of activation of this novel scheme and the amount of LS to be activated is to be based on a logic taking account of:

- $\quad$ the SC active power injections

- $\quad$ the total system inertia level

For the Baltic power grid an uniform distribution of the SC in the grid is determined. The list of contingencies relevant for this scheme is static, definite, and coherent. This lays a foundation to create a dedicated automation concept for rapid LS scheme to ensure frequency control for Baltic power system in island mode in order to prevent socioeconomic costs caused by restrictions on power generation and imports to ensure safe island mode operation.

To determine the practical thresholds of system inertia level and the SC injection coefficients suitable for the implementation of the novel LS method and its operation algorithm, a detailed dynamic simulation in the relevant practical power grid have to be conducted taking in account the detailed grid topology. Such an analysis has to be done for different generation-load scenarios with varying total inertia levels of the power system. Such an in-depth analysis can provide a foundation for practical implementation algorithms of the proposed LS method in the relevant AC power system.

Several different automation concepts can be used to implement the proposed LS method in practice. The SC active power injection measurements can trigger a SCADA based LS algorithm which will calculate the amount of load-shedding needed and activate the load-shedding relays. The function of measuring the active power can be assigned to the terminals of microprocessor based relay protection (for example as an addition to out-of-step protection automation) since these devices use active and reactive components of the vectors of currents and voltages: Ua, Ur and Ia, Ir. [38,39] The measurements of this values at times $t$ and $t+1$ allow as to calculate the total active power injection based on elementary arithmetic operations according to Equation (6):

$$
\Delta \mathrm{P}(\mathrm{t}+1)=\mathrm{U}_{\mathrm{a}(\mathrm{t}+1)} \mathrm{I}_{\mathrm{a}(\mathrm{t}+1)}+\mathrm{U}_{\mathrm{r}(\mathrm{t}+1)} \mathrm{I}_{\mathrm{r}(\mathrm{t}+1)}-\left(\mathrm{U}_{\mathrm{a}(\mathrm{t})} \mathrm{I}_{\mathrm{a}(\mathrm{t})}+\mathrm{U}_{\mathrm{r}(\mathrm{t})} \mathrm{I}_{\mathrm{r}(\mathrm{t})}\right),
$$

Figure 14 depicts a potential scheme for the SC measurement arrangement.

A flowchart of the proposed UFLS algorithm is presented in Figure 15. The voltage and current phasors are collected from PMUs as in Figure 14, and $\Delta \mathrm{P}_{\mathrm{SC}}=\sum_{\mathrm{i}=1}^{\mathrm{N}} \Delta \mathrm{P}_{\mathrm{SC} \_\mathrm{i}}$ is computed according with Equation (6). Load shedding sequence is triggered when $\Delta \mathrm{P} \_\mathrm{SC}$ exceeds the minimum allowed imbalance value $P_{\min }$. At next step the amount of load to be shed $\mathrm{P}_{\text {load_LS }}$ is calculated. The $\mathrm{K}$ coefficient is dependent on the percentage the non-synchronous sources constitute in total generated power. For a $100 \%$ non-synchronous generation, $\mathrm{K}=1$ and $\mathrm{P}_{\text {load_LS }}=\mathrm{P}_{\mathrm{SC}}$. It should be also noted, that for a simplistic case the coefficient could be set to $K=1$. Such setting suits all configurations of the network and all generation types' scenarios because over-shedding will never happen; but we still benefit from the quick tripping of certain amount of load. The final step is sending a trip commands to appropriate relays/IEDs according with calculated $\mathrm{P}_{\text {load_LS. }}$.

The proposed here LS scheme triggers (SC injections) can as well be used in the automation algorithms for triggering of fast frequency reserve such as primary reserve provided by battery energy storage units etc.

One of the biggest challenges for the practical implementations of the proposed LS scheme as seen by the authors would be transmitting the disconnection commands to hundreds or even thousands of loads. One of the solutions to this may be involving load aggregators which can be used for a number of purposes, including demand response $[40,41]$. 


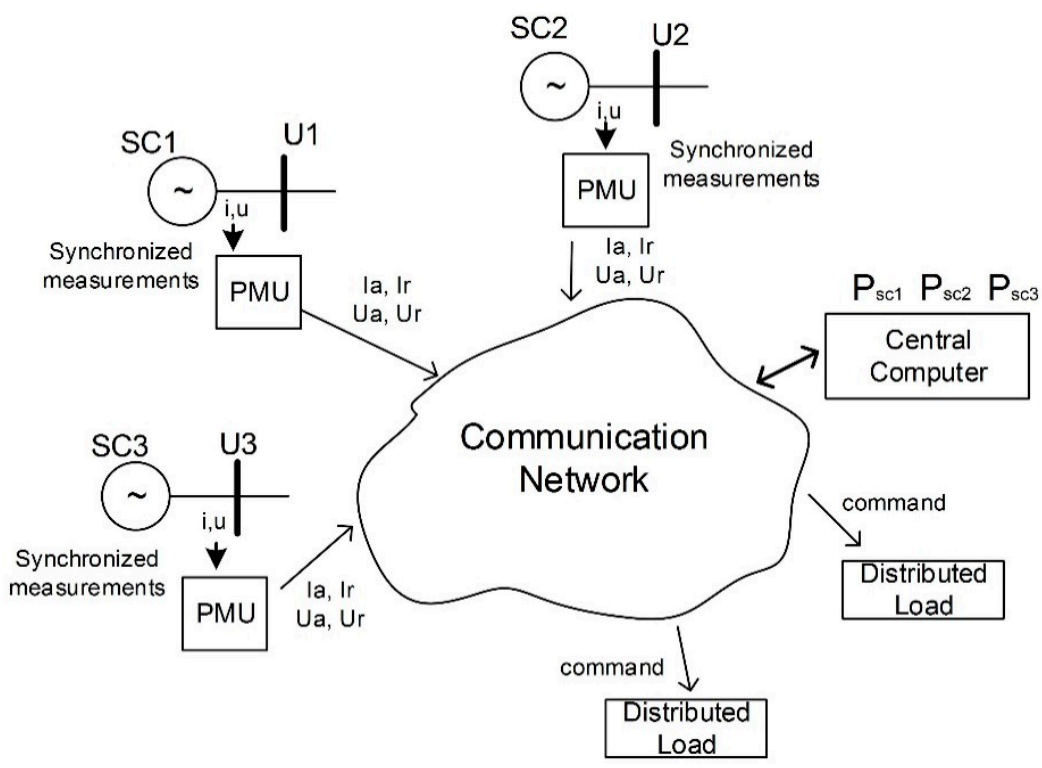

Figure 14. Potential scheme SC measurement arrangement for the proposed LS method tripping.

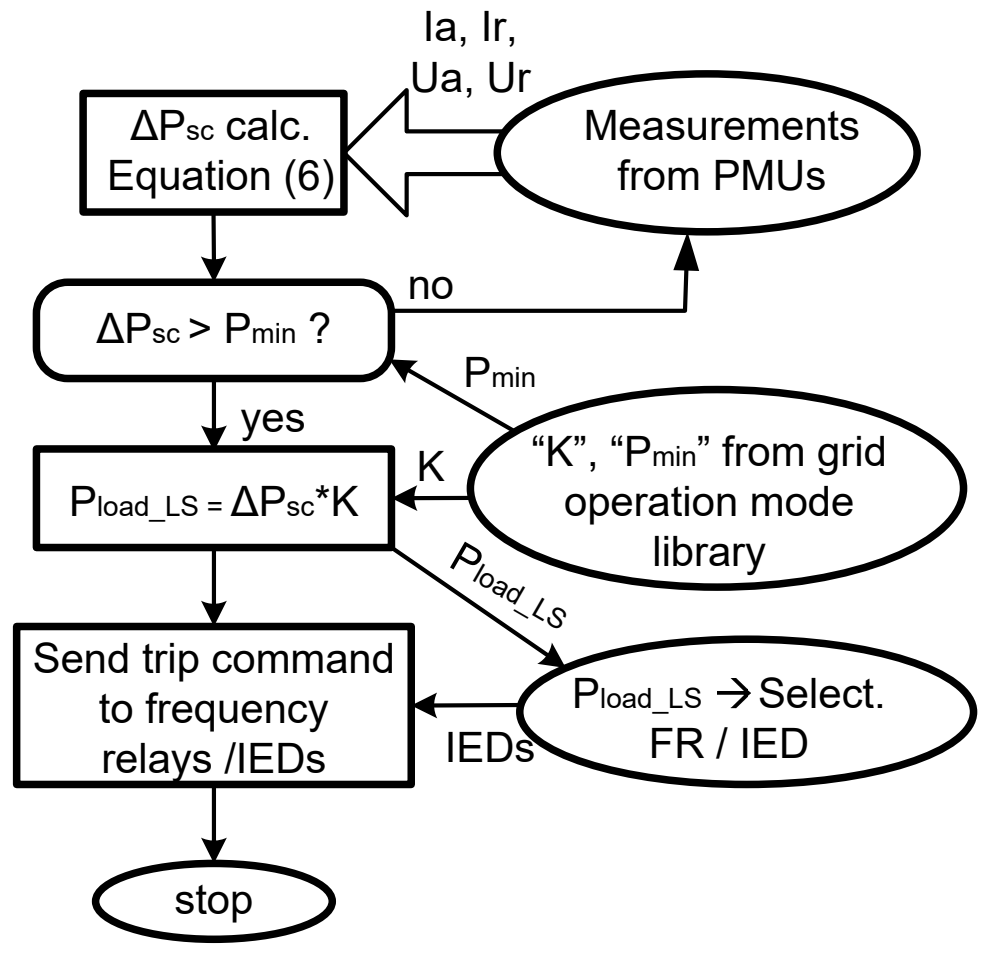

Figure 15. Potential execution algorithm.

\section{Conclusions}

The study shows that synchronous condensers in an AC power system respond with active power injections during a loss-of-generation incident. These injections are almost instant are of considerable size and well measurable. The injections vary with the size of the tripped generator and are affected by the electrical distance between the SC itself and the tripped generator.

The test case set simulations show that the proposed LS method is best suited for low system inertia power systems and the proposed LS approach significantly improves the postcontingency frequency response and the frequency stability of low inertia power systems. 
The study concludes that a proposed LS method based on the active power injections by the SC can have a right to be used. To develop the proposed LS concept further studies on the relevant power system topology, with real SC locations in the HV grid and on different total system inertia levels are needed. This will help to determine all the relevant parameters for the design and operation of a practical LS algorithm based on the proposed LS method.

Author Contributions: The contributions of the authors to this paper are as follows: the main idea was proposed by all the authors. A.S. and G.J. contributed to the methodology and data supervision. D.G., A.U. and J.S. performed the simulations for the case study and the paper writing-original draft preparation. All authors have read and agreed to the published version of the manuscript.

Funding: This article has been supported: by Latvian Council of Science, project: Management and Operation of an Intelligent Power System (I-POWER) (No. lzp-2018/1-0066) and by the Ministry of Economics of the Republic of Latvia, project "Future-proof development of the Latvian power system in an integrated Europe (FutureProof)", project No. VPP-EM-INFRA-2018/1-0005 and project "Innovative smart grid technologies and their optimization (INGRIDO)", project No. VPP-EMINFRA-2018/1-0006.

Institutional Review Board Statement: Not applicable.

Informed Consent Statement: Not applicable.

Data Availability Statement: The data presented in this study are available on request from the corresponding author.

Conflicts of Interest: The authors declare no conflict of interest.

$\begin{array}{ll}\text { Abbreviations } \\ \text { LS } & \text { Load shedding } \\ \text { UFLS } & \text { Under-frequency load shedding } \\ \text { ROCOF } & \text { Rate of change of frequency } \\ \text { AC } & \text { Alternating current } \\ \text { EU } & \text { European Union } \\ \text { MV /HV } & \text { Medium voltage/high voltage } \\ \text { UPS } & \text { Unified Power System of Russia } \\ \text { HVDC } & \text { High voltage direct current } \\ \text { CHP } & \text { Combined heat and power } \\ \text { ENTSO-E } & \text { European Network of Transmission System Operators for Electricity } \\ \text { TSO } & \text { Transmission systems operator } \\ \text { SC } & \text { Synchronous condenser } \\ \text { COI } & \text { Centre of inertia } \\ \text { TEC2 } & \text { Riga TEC2 CHP power plant } \\ \text { HPP } & \text { Hydro power plant }\end{array}$

\section{References}

1. UN Framework Convention on Climate Change. The Paris Agreement; UN Framework Convention on Climate Change: Rio de Janeiro, Brazil, 2016.

2. European Union. 2030 Climate \& Energy Framework; European Union: Brussels, Belgium, 2020.

3. European Union. Integrated National Energy and Climate Plan; European Union: Brussels, Belgium, 2020.

4. Germany Trade \& Invest. Business Opportunities in Germany; Germany Trade \& Invest: Berlin, Germany, 2018 ; p. 4.

5. Dreidy, M.; Mokhlis, H.; Mekhilef, S. Inertia response and frequency control techniques for renewable energy sources: A review. Renew. Sustain. Energy Rev. 2017, 69, 144-155. [CrossRef]

6. Tielens, P.; van Hertem, D. Grid Inertia and Frequency Control in Power Systems with High Penetration of Renewables. In Proceedings of the Young Researchers Symposium in Electrical Power Engineering, Delft, The Netherlands, 16-17 April 2012.

7. Moser, A. Planung und Betrieb von Elektrizitätsversorgungssytemen, Skriptum zur Vorlesung; IAEW: Aachen, Germany, 2012; pp. 151-153.

8. Machowski, J.; Bialek, J.W.; Bumby, J.R. Power System Dynamics, 2nd ed.; John Wiley \& Sons: Aachen, Germany, $2008 ;$ p. 171. 
9. Delfino, B.; Massucco, S.; Morini, A.; Scalera, P.; Silvestro, F. Implementation and comparison of different under frequency load-shedding schemes. In Proceedings of the 2001 Power Engineering Society Summer Meeting (Cat. No.01CH37262), New York, NY, USA, 16-18 October 1989; IEEE: Piscataway, NJ, USA, 2001; Volume 1, pp. 307-312.

10. Rudez, U.; Mihalic, R. Comparison of adaptive UFLS schemes in modern power systems. In Proceedings of the 2010 IEEE Electrical Power \& Energy Conference, San Diego, CA, USA, 22-26 July 2012; IEEE: Piscataway, NJ, USA, 2011 ; pp. $233-238$.

11. Ben Kilani, K.; Elleuch, M.; Hamida, A.H. Dynamic under frequency load shedding in power systems. In Proceedings of the 2017 14th International Multi-Conference on Systems, Signals \& Devices (SSD), Marrakech, Morocco, 28-31 March 2017; IEEE: Piscataway, NJ, USA, 2017; pp. 377-382.

12. Zare, F.; Ranjbar, A.; Faghihi, F. Intelligent topology-oriented load shedding scheme in power systems. In Proceedings of the 2019 27th Iranian Conference on Electrical Engineering (ICEE), Yazd, Iran, 30 April-2 May 2019; IEEE: Piscataway, NJ, USA, 2019; pp. 652-656.

13. Jianjun, Z.; Dongyu, S.; Dong, Z.; Yang, G. Load Shedding Control Strategy for Power System Based on the System Frequency and Voltage Stability (Apr 2018). In Proceedings of the 2018 China International Conference on Electricity Distribution (CICED), Tianjin, China, 17-19 September 2018; IEEE: Piscataway, NJ, USA, 2018; pp. 1352-1355.

14. Talaat, M.; Hatata, A.; Alsayyari, A.S.; Alblawi, A. A smart load management system based on the grasshopper optimization algorithm using the under-frequency load shedding approach. Energy 2020, 190, 116423. [CrossRef]

15. Rudez, U.; Mihalic, R. Trends in WAMS-based under-frequency load shedding protection. In Proceedings of the IEEE EUROCON 2017-17th International Conference on Smart Technologies, Ohrid, Macedonia, 6-8 July 2017; IEEE: Piscataway, NJ, USA, 2017; pp. 782-787.

16. European Commision. The Baltic Power System Between East and West Interconnections, JRC Science for Policy Report; European Commision: Brussels, Belgium, 2016.

17. AS Augstsprieguma Tīkls; Latvian TSO; Riga, Latvia. Personal communication, 2020.

18. NordPoolSpot. Available online: https://www.nordpoolgroup.com/ (accessed on 15 December 2020).

19. European Commision. Energy Security: The Synchronisation of the Baltic States' Electricity Networks-European Solidarity in Action; European Commision: Brussels, Belgium, 2019.

20. Junghans, G.; Silis, A.; Marcina, K.; Ertmanis, K. Role of Balancing Markets in Dealing with Future Challenges of System Adequacy Caused by Energy Transmission. Latv. J. Phys. Tech. Sci. 2020, 57, 48-56. [CrossRef]

21. Republic of Estonia. Estonia's 2030 National Energy and Climate Plan; Republic of Estonia: Talin, Estonia, 2019.

22. Republic of Latvia. Latvia's National Eenergy and Climate Plan 2021-2030; Republic of Latvia: Riga, Latvia, 2020.

23. Republic of Lithuania. National Eenergy and Climate Action Plan of the Republic of Lithuaniafor 2021-2030; Republic of Lithuania: Vilnius, Lithuania, 2021.

24. Ivanova, P.; Sauhats, A.; Linkevics, O. Towards optimization of combined cycle power plants' start-ups and shut-down. In Proceedings of the 2016 57th International Scientific Conference on Power and Electrical Engineering of Riga Technical University (RTUCON), Riga, Latvia, 13-14 October 2016; IEEE: Piscataway, NJ, USA, 2016; pp. 1-6.

25. Payerl, C. Introduction to ABB Synchronous Condenser Offering-A Solution to Improve Grid Strength; IEEE: Piscataway, NJ, USA, 2020.

26. Szaba, C. Synchronous condensers. An old tool rediscovered to address new grid challenges. Power Eng. Int. 2017, 11, 1782-1789.

27. Terzija, V.V. Adaptive Underfrequency Load Shedding Based on the Magnitude of the Disturbance Estimation. IEEE Trans. Power Syst. 2006, 21, 1260-1266. [CrossRef]

28. Anderson, P.M.; Mirheydar, M. An adaptive method for setting underfrequency load shedding relays. IEEE Trans. Power Syst. 1992, 7, 647-655. [CrossRef]

29. Rudez, U.; Mihalic, R. Monitoring the First Frequency Derivative to Improve Adaptive Underfrequency Load-Shedding Schemes. IEEE Trans. Power Syst. 2011, 26, 839-846. [CrossRef]

30. Laghari, J.A.; Mokhlis, H.; Karimi, M.; Abu Bakar, A.H.; Mohamad, H. A New Under-Frequency Load Shedding Technique Based on Combination of Fixed and Random Priority of Loads for Smart Grid Applications. IEEE Trans. Power Syst. 2014, 30, $2507-2515$. [CrossRef]

31. Deb, N.; Papari, B.; Ozkan, G.; Badr, P.R.; Hoang, P.H.; Edrington, C.S. An Intelligent Load Shedding Scheme for the Mi-cro-grid in Shipboard Power System Using Probabilistic Methods. In Proceedings of the 2020 Clemson University Power Systems Conference (PSC), Clemson, SC, USA, 10-13 March 2020.

32. Rudez, U.; Mihalic, R. Analysis of Underfrequency Load Shedding Using a Frequency Gradient. IEEE Trans. Power Deliv. 2011, 26, 565-575. [CrossRef]

33. Frigo, G.; Derviskadic, A.; Zuo, Y.; Paolone, M. PMU-Based ROCOF Measurements: Uncertainty Limits and Metrological Significance in Power System Applications. IEEE Trans. Instrum. Meas. 2019, 68, 3810-3822. [CrossRef]

34. Guzs, D.; Utans, A.; Sauhats, A.; Junghans, G.; Silinevics, J. Resilience of the Baltic power system when operating in island mode. In Proceedings of the 2020 IEEE 61th International Scientific Conference on Power and Electrical Engineering of Riga Technical University (RTUCON), Riga, Latvia, 5-7 November 2020; Institute of Electrical and Electronics Engineers (IEEE): Piscataway, NJ, USA, 2020; pp. 1-6.

35. Rubio, A.; Behrends, H.; Geißendörfer, S.; von Maydell, K.; Agert, C. Determination of the Required Power Response of Inverters to Provide Fast Frequency Support in Power Systems with Low Synchronous Inertia. Energies 2020, 13, 816. [CrossRef]

36. Siemens Power Technologies Inc. PSS/E-34 Program Operational Manual; Siemens Power Technologies Inc.: New York, NY, USA, 2019. 
37. Operation Technology Inc. ETAP Products \& Solutions Comprehensive, Integrated Suite of Power System Software Modules from Design to Operation; ETAP Electrical Power System Analysis Software; Operation Technology Inc.: Irvine, CA, USA, 1995.

38. Sauhats, A.; Svalova, I.; Svalovs, A.; Antonovs, D.; Utans, A.; Bochkarjova, G. Two-terminal out-of-step protection for mul-ti-machine grids using synchronised measurement. In Proceedings of the 2015 IEEE Eindhoven PowerTech, Eindhoven, The Netherlands, 29 June-2 July 2015.

39. Sauhats, A.; Utans, A.; Antonovs, D.; Svalovs, A. Angle Control-Based Multi-Terminal Out-of-Step Protection System. Energies 2017, 10, 308. [CrossRef]

40. Palensky, P.; Dietrich, D. Demand Side Management: Demand Response, Intelligent Energy Systems, and Smart Loads. IEEE Trans. Ind. Inform. 2011, 7, 381-388. [CrossRef]

41. Jabir, H.J.; Teh, J.; Ishak, D.; Abunima, H. Impacts of Demand-Side Management on Electrical Power Systems: A Review. Energies 2018, 11, 1050. [CrossRef] 